\title{
Women's Satisfaction of Maternity Care in Nepal and Its Correlation with Intended Future Utilization
}

\author{
Yuba Raj Paudel, ${ }^{1}$ Suresh Mehata, ${ }^{1}$ Deepak Paudel, ${ }^{2}$ Maureen Dariang, ${ }^{1}$ \\ Krishna Kumar Aryal, ${ }^{3}$ Pradeep Poudel, ${ }^{1}$ Stuart King, ${ }^{1}$ and Sarah Barnett ${ }^{4}$ \\ ${ }^{1}$ Nepal Health Sector Support Program, Ministry of Health and Population, Kathmandu 44600, Nepal \\ ${ }^{2}$ Department for International Development in Nepal, Country Office, Ekantakuna Road, Lalitpur 44600, Nepal \\ ${ }^{3}$ Nepal Health Research Council, Ministry of Health and Population, Kathmandu 44600, Nepal \\ ${ }^{4}$ Options Consultancy Services Limited, Devon House, 58 St. Katharine's Way, London E1W1LB, UK
}

Correspondence should be addressed to Suresh Mehata; sureshmehata@nhssp.org.np

Received 4 June 2015; Revised 14 October 2015; Accepted 19 October 2015

Academic Editor: Robert Gaspar

Copyright (C) 2015 Yuba Raj Paudel et al. This is an open access article distributed under the Creative Commons Attribution License, which permits unrestricted use, distribution, and reproduction in any medium, provided the original work is properly cited.

\begin{abstract}
The impact of rapid increase in institutional birth rate in Nepal on women's satisfaction and planned future utilization of services is less well known. This study aimed to measure women's satisfaction with maternity care and its correlation with intended future utilisation. Data came from a nationally representative facility-based survey conducted across 13 districts in Nepal and included client exit interviews with 447 women who had either recently delivered or had experienced complications. An eight-item quality of care instrument was used to measure client satisfaction. Multivariate probit model was used to assess the attribution of different elements of client satisfaction with intended future utilization of services. Respondents were most likely to suggest maintaining clean/hygienic health facilities (42\%), increased bed provision (26\%), free services (24\%), more helpful behaviour by health workers $(18 \%)$, and better privacy (9\%). Satisfaction with the information received showed a strong correlation with the politeness of staff, involvement in decision making, and overall satisfaction with the care received. Satisfaction with waiting time $(p=0.035)$, information received $(p=0.02)$, and overall care in the maternity care $(<0.001)$ showed strong associations with willingness to return to facility. The findings suggest improving physical environment and interpersonal communication skills of service providers and reducing waiting time for improving client satisfaction and intention to return to the health facility.
\end{abstract}

\section{Introduction}

The Government of Nepal has promoted institutional births through the expansion of birthing centers in existing peripheral health institutions and the availability of 24 -hour comprehensive emergency obstetric care at hospitals [1]. In addition, the Ministry of Health and Population (MoHP) introduced maternity incentives to reduce financial barriers to accessing institutional births in 2005, which evolved into free maternity care and transport incentives (the Aama program) in 2009 [2]. As a result of this demand generation and service expansion, the institutional birth rate tripled from $18 \%$ in 2006 to $55 \%$ in 2014 [3-6]. However, increasing the access and utilization of health services is unlikely to bring improved health outcomes unless services meet benchmarks for good quality [7]. The midterm review of current Nepal Health
Sector Program (NHSP II) acknowledged that attention to date has focused on improving access to care, and, although this needs to continue, more attention on quality of care is required as a matter of priority [8]. Furthermore, quality of care is also a central focus in the National Health Policy 2014 [9].

Women's experience and satisfaction are an important element of quality of maternity care [10, 11]. Satisfaction is a complex and multidimensional concept embracing structure, process, and outcome of care $[12,13]$. The literature suggests that factors such as women's participation in decision making during pregnancy and childbirth [14, 15], women's sense of control, both internal and external, over the whole process $[13,14]$, client-provider relationships [16], respectful care [7], and the physical environment of the maternity ward [15] are significant factors associated 
with women's satisfaction and future utilization of health services. A systematic review highlights the importance of staff attitude and respectful behaviour over pain management or sociodemographic factors on maternity client satisfaction [17]. Hence, to understand service user's perception of quality service, and interaction among different elements of quality of care, it is necessary to study correlation of satisfaction with these elements. Administrators and managers can use such information to improve quality score in a cost-effective way.

Client satisfaction measures the ability of services to meet consumers' expectations [18], and is an important determinant of the choice of health facility and of future utilization of services [19-22]. Satisfied clients will be more likely to return in the future and recommend the institution to their relatives/friends $[23,24]$. A study conducted in outpatient setting to investigate association of patient satisfaction with return behaviour concluded that many of the standard elements of quality of care have a very less effect on return behaviour, whereas time and attention paid to health care users were the strongest predictor of returning to a health institution [24]. However, to our knowledge, no studies have examined the association between the likelihood of returning to facility with maternity clients' satisfaction in Nepal.

Increased institutional births are being successfully promoted in Nepal; however, the impact of rapid increases in utilisation on quality of care, women's experience, and client satisfaction is less well known. This paper aims to measure client satisfaction with key elements of quality of care and study the correlation between key quality measures and future utilisation. Understanding women's views and experiences provides an important insight for managers and policy makers to change practices to effectively address their needs and expectations and benefit future clients [25].

\section{Methods}

2.1. Data Source and Sampling. This paper used data from a nationally representative cross-sectional facility-based survey conducted by some of the authors: Service Tracking Survey (STS) 2013 [26]. Three questionnaires were administered in the survey: facility assessment, exit interviews with maternity clients, and exit interviews with outpatients. The survey provided national estimates for key reproductive, maternal, neonatal, and child health indicators related to availability, readiness, and quality of care. The detailed methodology is presented in the STS 2013 final report [26]. Briefly, a two-stage sampling design was adopted to select health facilities. In the first stage, five districts from Terai, five districts from hill, and 3 districts from mountain were selected considering one district (primary sampling unit) that was randomly selected from 13 subregions of Nepal. In the second stage, all district hospitals and Primary Health Care Centres (PHCCs) from selected districts were included, and sub/health posts (S/HPs) were selected using equal probability selection method (EPSEM). The selected health facilities included 17 public hospitals, 39 PHCCs, 100 HPs, and 86 SHPs. A total of 447 exit interviews were conducted with women who had either delivered recently or had experienced obstetric complications
(87\% in hospitals, $8 \%$ in PHCCs, $4 \%$ in HPs, and less than $1 \%$ in SHPs). Due to low caseload and the short data collection time period, fewer clients were interviewed in HPs and SHPs.

2.2. Data Collection and Quality Assurance. Data collection was carried out between July and August 2013. Training Manual, Survey Field Manual, and Data Entry Manual were produced and used throughout the training, data collection, and data entry to ensure quality and consistency. Enumerators had a five-day training, focusing on objectives, approach, survey instruments, ethical issues, reporting, and other operational issues. Supervision and monitoring visits to the survey sites were made soon after survey started to identify and rectify any problems early on. Completed questionnaires were checked by the supervisors in the district before sending them to the central office for data entry. Feedback was provided to the enumerators during data collection.

2.3. Data Cleaning, Coding, and Entry. Completed questionnaires were checked for completeness, consistency of data, and the presence of outliers before data entry. Any suspect data were cross-checked against hard copies of completed questionnaires. The databases were developed in CSPro 5.0. The databases were pretested before data entry start and any errors were eliminated.

\subsection{Measures}

2.4.1. Client Satisfaction. Client satisfaction was measured using an eight-item instrument. The items covered several key dimensions of client satisfaction: accessibility (one question), interpersonal communication (two questions), physical environment (two questions), clinical care (two questions), and decision making (one question). The 8 items of quality of care showed a high internal consistency (Cronbach's alpha $=0.74$ ) to measure client satisfaction. The responses were marked using a five-point Likert scale [27]: (1) fully dissatisfied, (2) unsatisfied, (3) neutral, (4) satisfied, and (5) fully satisfied. The survey measured the likelihood of visiting the facility again with the question "if you are willing to have another baby, would you like to visit this facility for childbirth?”

2.4.2. Data Analysis. We acknowledged the weighing of the data, the approximate stratification, and the two-level clustering while computing statistical tests, using the survey functions of STATA 12 SE Version.

The sample weight was used during the descriptive bivariate and multivariate analysis. Descriptive analysis was carried out for all dimensions of clients' satisfaction (Table 3). Pearson's correlation was calculated between levels of satisfaction with waiting time, information received, provider competency, politeness of staff, involvement in decision making, cleanliness of facility, privacy, overall care received at the facility, and intended future use of services (Table 2). A correlation coefficient of $\geq 0.3$ is considered to be a strong correlation for this analysis. A multivariate probit regression model was used to investigate factors associated 


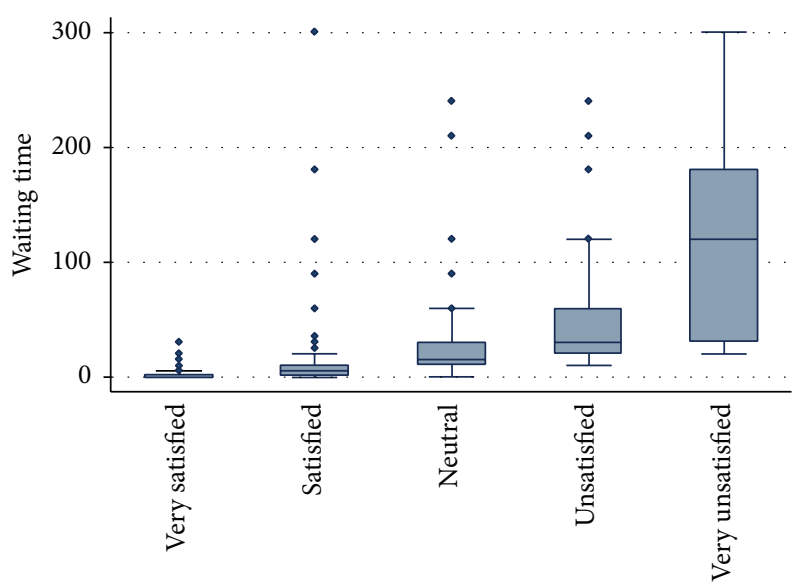

FIGURE 1: Waiting time (minutes) according to level of satisfaction with waiting time $(N=447)$.

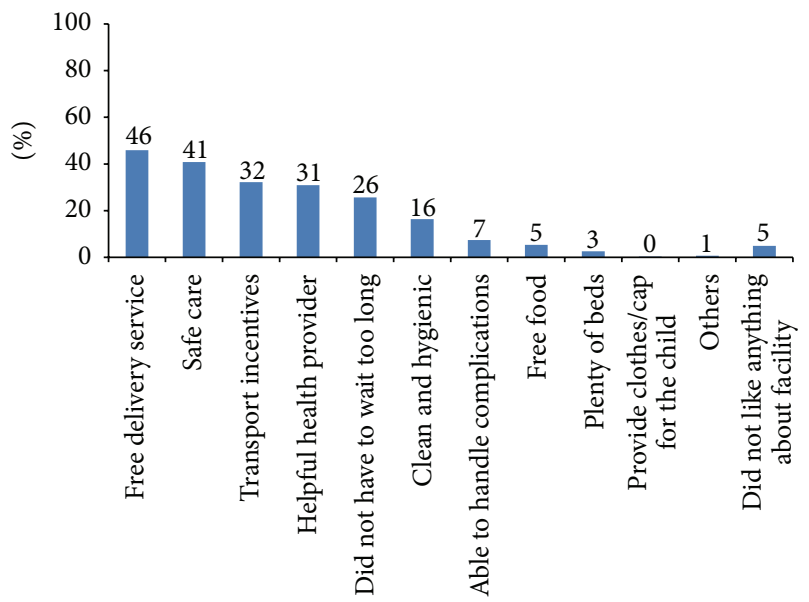

FIGURE 2: Maternity clients' likes about delivery care $(N=447)$.

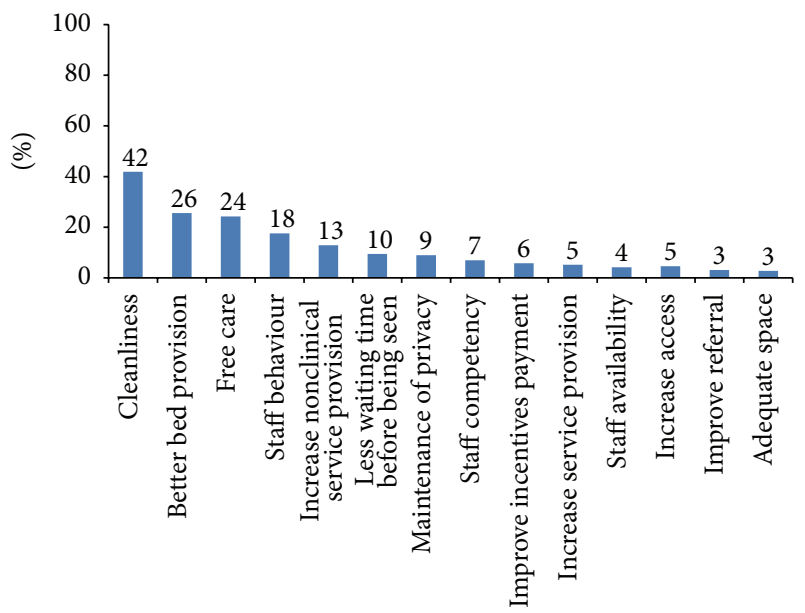

FIGURE 3: Maternity clients' recommendations $(N=447)$.

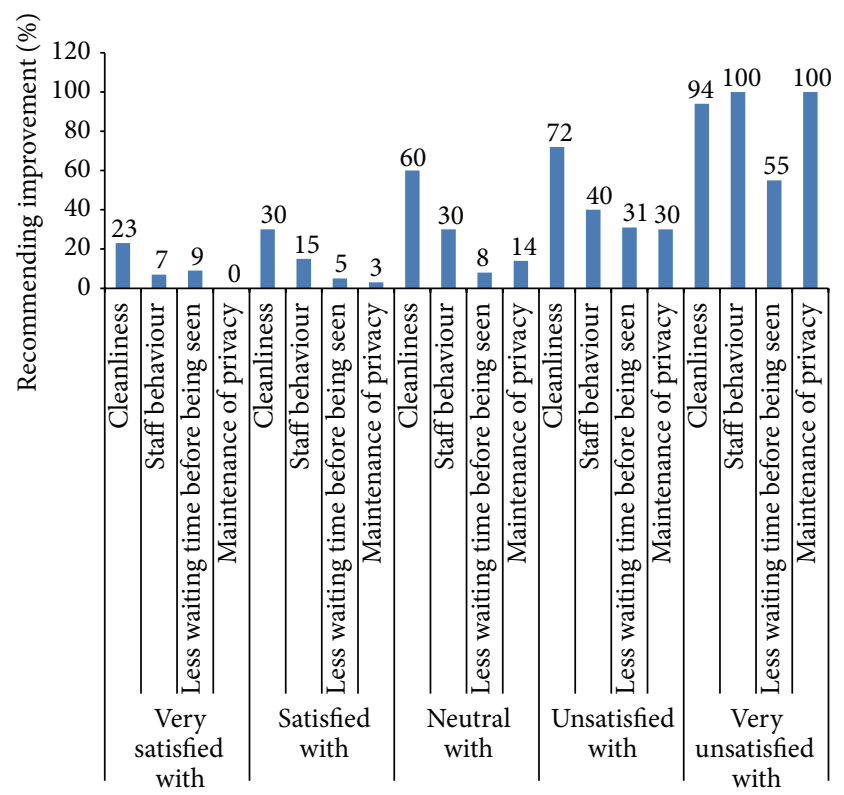

FIGURE 4: Maternity clients' recommendations according to level of satisfaction $(N=447)$.

with intention of future use of services (Table 4). The multivariate model included 8 items of client satisfaction. Level of satisfaction according to waiting time was investigated and presented in a box plot (Figure 1). Maternity clients' likes and recommendations to physical environment, staff behaviour, and facilities were calculated as percentage of total respondents (Figures 2 and 3). Furthermore, client's recommendations to improve various attributes (waiting time, cleanliness, privacy, and staff behaviour) according to their level of satisfaction to each item were also investigated (Figure 4).

\section{Results}

Table 1 depicts sociodemographic characteristics and accessibility factors for maternity clients. Among 447 respondents, nearly two-thirds were $20-29$ years old (67\%) and more than one-third were Brahmin/Chhetri (37\%). Nearly half (46\%) of the total sample had completed secondary education. It took less than 30 minutes for around one-third of the respondents (37\%) to reach the health facility, while it took more than an hour to reach health facility for more than a quarter $(26 \%)$ of respondents.

The percentages of clients satisfied with individual elements of quality of care are presented in Table 2. Most of them were satisfied with (very satisfied and satisfied) care received at the facility (86\%), provider's skills (85\%), politeness of staff $(83 \%)$, waiting time (80\%), involvement in decision making (77\%), cleanliness $(70 \%)$, information received $(69 \%)$, and assured confidentiality (67\%). Mean satisfaction score was the highest for level of skill of service provider (4.0) and was the lowest for cleanliness of the facilities (3.4).

Table 3 shows the correlation between the various elements of client satisfaction. Satisfaction with information 
TABLE 1: Sociodemographic characteristics and geographical/accessibility factors of maternity clients $(N=447)$.

\begin{tabular}{|c|c|c|}
\hline Variables & $N$ & $\%$ \\
\hline \multicolumn{3}{|l|}{ Sociodemographic characteristics } \\
\hline \multicolumn{3}{|l|}{ Age (years) } \\
\hline$<20$ & 109 & 24.38 \\
\hline $20-29$ & 300 & 67.11 \\
\hline$\geq 30$ & 38 & 8.50 \\
\hline \multicolumn{3}{|l|}{ Parity } \\
\hline Primigravida & 263 & 58.84 \\
\hline Multigravida & 184 & 41.16 \\
\hline \multicolumn{3}{|l|}{ Education status } \\
\hline Never attended school & 92 & 20.58 \\
\hline Primary education & 57 & 12.75 \\
\hline Secondary education & 204 & 45.64 \\
\hline Further education & 94 & 21.03 \\
\hline \multicolumn{3}{|l|}{ Caste/ethnicity } \\
\hline Brahmin/Chhetri & 164 & 36.69 \\
\hline Terai/Madhesi other castes & 91 & 20.36 \\
\hline Dalits & 68 & 15.21 \\
\hline Newar & 15 & 3.36 \\
\hline Janajati & 96 & 21.48 \\
\hline Muslim & 13 & 2.91 \\
\hline \multicolumn{3}{|l|}{ Geographic/assessable factors } \\
\hline \multicolumn{3}{|l|}{ Ecological zone } \\
\hline Mountain & 38 & 8.50 \\
\hline Hill & 136 & 30.43 \\
\hline Terai & 273 & 61.07 \\
\hline \multicolumn{3}{|l|}{ Place of residence } \\
\hline Urban & 346 & 77.40 \\
\hline Rural & 101 & 22.60 \\
\hline \multicolumn{3}{|l|}{ Reaching time (minutes) } \\
\hline$<30$ & 167 & 37.36 \\
\hline $30-59$ & 160 & 35.79 \\
\hline$\geq 60$ & 120 & 26.85 \\
\hline
\end{tabular}

received showed a strong correlation with politeness of staff, involvement in decision making, and satisfaction about care at facility. Likewise, satisfaction with skill of service provider also showed a strong correlation with politeness of staff and satisfaction with care received. Furthermore, a strong correlation was observed between future use of services and the overall care received at the facility.

Determinants for willingness to visit the facility again are shown in Table 4. Just more than half of the respondents (56\%) reported that they were willing to visit the facility again (data not shown). Multivariate analysis revealed that satisfaction with waiting time (coef.: 0.47 ; 95\% CI: $0.03-$ 0.90), information received at the facility (coef.: 0.64; 95\% CI: 0.09-1.19), and satisfaction with overall care at facility (coef.: 1.03 ; 95\% CI: $0.55-1.50$ ) were positively associated with willingness to visit the facility again. No significant association was observed with willingness to visit the facility again and politeness of staff, involvement in decision making, cleanliness of facility, and privacy at facility.

Figure 1 describes satisfaction with waiting time versus waiting time duration at the facility, and study revealed that the likelihood of dissatisfaction with waiting time is increased with increase in waiting time at the facility. The significant difference in waiting time was observed by level of satisfaction; the lowest waiting time was observed for those who were very satisfied (mean: 2 minutes and median $=$ 0 minutes) compared to those who were very unsatisfied (mean: 144 minutes and median: 120 minutes).

Maternity clients were asked what they liked or disliked about the childbirth care they had received. Most commonly, clients liked the provision of free delivery services (46\%); safe care (41\%); transportation incentives (36\%); the helpful attitude of health workers; short waiting times; and the clean and hygienic conditions of health facilities (Figure 2). The most common dislikes reported by maternity clients were a lack of cleanliness (22\%), a scarcity of beds and bed linen (21\%), and a lack of privacy (9\%).

Figure 3 presents major recommendations made by maternity clients to improve services. Most of them suggested maintaining clean/hygienic health facilities (42\%), better bed provision $(26 \%)$, improvement/continuity of free services (24\%), more helpful behaviour from health workers (18\%), less waiting time $(10 \%)$, and better privacy at the health facilities (9\%). About $17 \%$ of maternity clients responded that everything was good in the facility and required no improvement.

Figure 4 shows recommendations of maternity clients by level of satisfaction to cleanliness, staff behavior, waiting time, and privacy. More than 9 in 10 (94\%) of clients who were very unsatisfied with cleanliness recommended improving the cleanliness of the facility. More than half of clients who were satisfied or very satisfied with cleanliness also recommended improving cleanliness of the facilities. All of the clients who were very unsatisfied with staff behavior and privacy recommended improving staff behaviour, and privacy, respectively, in the facility. More than half of the clients (55\%) who were very unsatisfied with waiting time made recommendation to reduce waiting time between arriving at the facility and being seen by service provider.

\section{Discussion}

This study measured client satisfaction using 8 items of quality of care. Mean satisfaction score was the highest for level of skill of service providers. On one hand, clients may not be able to differentiate dimensions of competence and incompetence. On the other hand, clients may relate provider skill with politeness and good communication skill of service providers as shown by correlation matrix (Table 2). Previous studies have also found that frequency of explanations [15], skillful interactions, and responsiveness of service provider to client's need $[28,29]$ were strongly associated with satisfaction with maternity care received. Furthermore, quality of care might have different meaning to different individuals [10]. Relational component could be more important to 
TABLE 2: Percentage of the mothers by level of satisfaction with perinatal care $(N=447)$.

\begin{tabular}{|c|c|c|c|c|}
\hline Dimension & Very satisfied & Satisfied & Mean satisfaction score* & Standard deviation \\
\hline \multicolumn{5}{|l|}{ Accessibility } \\
\hline Waiting time & 27.9 & 52.5 & 3.9 & 0.95 \\
\hline \multicolumn{5}{|l|}{ Interpersonal communication aspects } \\
\hline Information received & 11.2 & 57.7 & 3.7 & 0.70 \\
\hline Politeness of staff & 12.8 & 69.9 & 3.9 & 0.64 \\
\hline \multicolumn{5}{|l|}{ Physical environment } \\
\hline Assurance of confidentiality & 4.0 & 62.7 & 3.6 & 0.73 \\
\hline Cleanliness of facility & 7.2 & 62.4 & 3.4 & 0.99 \\
\hline \multicolumn{5}{|l|}{ Decision making } \\
\hline Involvement in decision making & 8.9 & 68.3 & 3.8 & 0.65 \\
\hline \multicolumn{5}{|l|}{ Technical aspect } \\
\hline Level of skill of provider & 17.3 & 67.6 & 4.0 & 0.62 \\
\hline Care at facility & 12.9 & 72.8 & 3.9 & 0.60 \\
\hline
\end{tabular}

${ }^{*}$ The satisfaction score was constructed by giving scores: fully satisfied $=5$; satisfied $=4$; neutral $=3$; dissatisfied $=2$; and fully dissatisfied $=1$.

some clients compared to technical competency of service providers [7].

Cleanliness of the facility was a major concern among both satisfied and unsatisfied clients. Just more than twothirds of the clients were satisfied or very satisfied with cleanliness. While a similar proportion of clients were satisfied or very satisfied with cleanliness in service tracking survey of 2012 [30], higher dissatisfaction with cleanliness of maternity facilities was shown in studies conducted in Malawi [21] and Kenya [20] in comparison to current study. Since cleanliness is easily discernible to clients in comparison to other aspects of quality of care, this could have resulted in lower satisfaction with cleanliness. However, poor cleanliness in maternity wards has been reported in previous studies conducted in Nepal and elsewhere [20, 21, 31]. A study that used pattern approach to studying satisfaction to maternity care showed that women who were unsatisfied with physical environment were more likely to be educated [29]; since more than two-thirds of clients in current study had secondary or higher education, cleanliness could have been pointed out clearly. It is interesting to note that almost a quarter of clients who were very satisfied with cleanliness also expressed recommendation to improve cleanliness of the facilities (Figure 4).

Satisfaction with information received showed a strong correlation with politeness of service provider, skill of service provider, and satisfaction toward the care received. This finding suggests that women want to be well informed about the process and outcome of childbirth and most likely relate it to competency of service provider. A good communication between provider and clients is highly valued by maternity clients [25]. Although research has shown that cognitive and emotional support for women during labour is beneficial for well-being of women and newborn by reducing duration of labour and possibility of postpartum depression [32], many studies have highlighted that maternity experience in medical setting has been dominated by professionals. Health workers share very less information with mothers about childbirth process, let alone participating them in decision making about childbirth [25, 33]. Furthermore, although clients expect service providers to have knowledge and technical competency, their satisfaction is mainly determined by behaviour, communication skill of service providers, and amount of time spent in interaction $[17,34]$. Hence, maternity health care need to be restructured in a way to cater to the multidimensional needs of women during childbirth.

Only two-thirds of clients were satisfied or very satisfied with privacy in the facility. A study conducted in a maternity health centre from Malawi found that, despite being treated politely, lack of auditory and visual privacy led women to not using a maternity facility [21]. Hence provisions to ensure privacy in health facilities are warranted.

Similar to the findings from other studies $[18,34,35]$, the current study found that client satisfaction decreased with higher waiting time. Being seen only after 2 hours of arriving at facility could have brought feeling of being ignored at the health facility and brought dissatisfaction. Another possible explanation for dissatisfaction with longer waiting time could be due to less time to talk with service providers owing to overcrowded facility, despite having to wait for long time. Furthermore, a study conducted in Ethiopia found that delay in receiving care once women had reached the maternity hospital was mainly due to operational issues such as "shortage of medicines, blood, equipment, or to the absence of qualified/competent staff, poor organization of care or combination of all" [36]. Although current study could not investigate what caused longer waiting time, it is likely that poor organization and readiness of care could have resulted in longer waiting time since Jahn et al. found that conduction of caesarean section took an average of 4.5 hours (range of 40 minutes to 11 hours) in rural Nepal once the decision to operate has been made [37]. Longer waiting time was reported to be associated with the worst outcomes among women who experienced similar childbirth complications [36]. Increased demand with staff shortage is likely to result in overcrowded facilities, longer waiting time, poor behaviour from overburdened staff, and shortage of supplies [38], which 


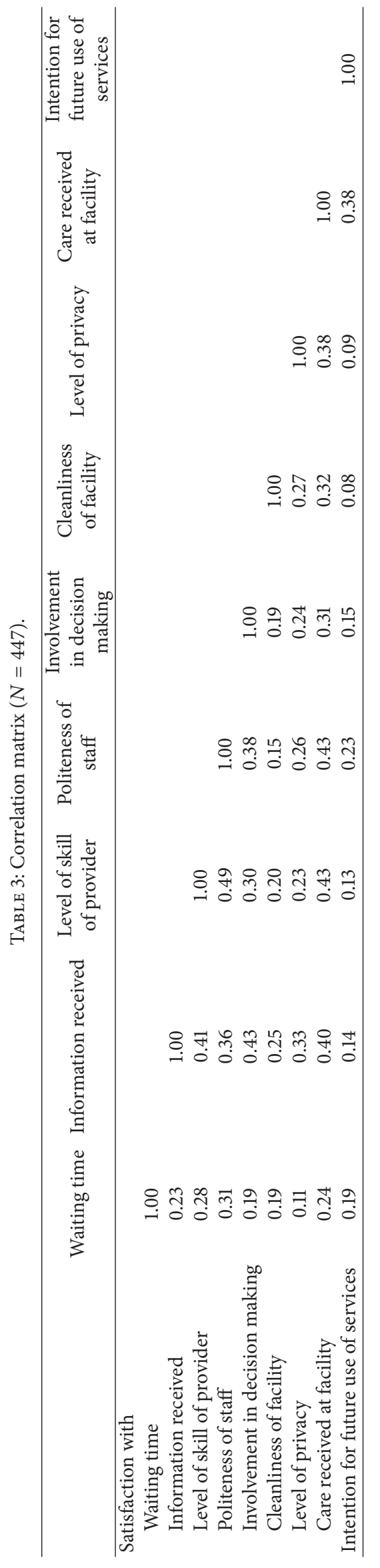


TABLE 4: Determinants of willingness to return to facility $(N=447)$.

\begin{tabular}{|c|c|c|c|c|c|c|}
\hline & \multicolumn{4}{|c|}{ Linearized } & \multicolumn{2}{|c|}{$95 \%$ confidence interval } \\
\hline & Coef. & Std. err. & $z$ & $p$ & Lower & Upper \\
\hline Waiting time & 0.47 & 0.22 & 2.11 & 0.035 & 0.03 & 0.90 \\
\hline Information received & 0.64 & 0.28 & 2.29 & 0.022 & 0.09 & 1.19 \\
\hline Politeness of staff & 0.00 & 0.26 & -0.02 & 0.986 & -0.51 & 0.50 \\
\hline Privacy at facility & -0.39 & 0.24 & -1.64 & 0.100 & -0.86 & 0.08 \\
\hline Cleanliness of facility & -0.18 & 0.20 & -0.91 & 0.365 & -0.56 & 0.21 \\
\hline Involvement in decision making & 0.15 & 0.22 & 0.68 & 0.500 & -0.29 & 0.59 \\
\hline Level of skill of provider & -0.28 & 0.27 & -1.05 & 0.292 & -0.81 & 0.24 \\
\hline Overall care at facility & 1.03 & 0.24 & 4.24 & $<0.001$ & 0.55 & 1.50 \\
\hline
\end{tabular}

are often interrelated. Since childbirth is a stressful event, women want quick response when they need a support, while a longer waiting time causes frustration/dissatisfaction [34].

Current study found an association of willingness to return to the facility with satisfaction to waiting time, information received, and overall care in the facility. These results are in concert with findings from other recent studies [23, 34, 39-41]. A study from the US also showed that reducing waiting-room wait time in a primary-care practice significantly improved patient satisfaction and willingness to refer relatives/friends to the facility [41]. Willingness to refer friends/relatives was treated as a proxy measure for overall satisfaction and willingness to return to the primary care. A previous study concluded that service providers need to assess expectation of clients regarding realistic waiting time in order to meet their expectations and improve satisfaction [34]. Reduced intention to return to health facility among those who had to wait for long time could be attributed to poor outcomes among mothers having to wait longer before being seen [36].

Consistent with findings from previous studies [23, 40], information received from service providers, and patient satisfaction have been shown to be a strong correlate of return behaviour in the current study. Garman et al. showed that satisfied clients were more likely to return to the hospital [24]. The clients who returned for subsequent health care were more likely to have received adequate information and attention from service providers. The time and attention provided to the patients and their families counted a lot in increasing likelihood for subsequent visit to the same institution. Hence, high quality patient-clinician relationship is instrumental for client satisfaction. Similarly, Al-Mailam studied satisfaction of hospital care and found that satisfaction to overall care was significantly associated with satisfaction to nursing care. And satisfaction to nursing care showed a strong correlation with intention to return to the hospital [23]. Studies show that if nurses are satisfied with their own jobs, they will behave with clients in a respectful manner $[23,42]$. Since most of the care in maternity care is associated with nursing care, behaviour of nurses is likely to determine overall satisfaction and probability of returning in the future.
The findings of this study need to be interpreted in the light of some limitations. Since the majority of women were interviewed within 24 hours of birth in institution, there is a possibility of women being less critical due to the joy of childbirth and overlooking negative experiences due to a phenomenon called halo effect [43]. Further, women of early postnatal period feel difficulty to report negative experiences of childbirth if the child is healthy [44]. In addition, being interviewed within institutional setting might have caused women to response in a positive way. Although other studies have used willingness to recommend the facility as a measure of satisfaction, this study only examined willingness to return to facility. However, researchers have treated willingness to recommend the health facility to friends/relatives as a proxy measure for willingness to return to health facility [41]. Since only few maternity clients (5\% of total sample) could be interviewed from sub/health posts, the findings from this study might be closer to the scenario of PHCCs and hospitals of Nepal. We measured intention to return to the health facility for next childbirth which could be different to their actual behaviour. First-time mothers, less educated [29] ones, or who gave childbirth at institutions for the first time might have different perception of quality of care compared to mothers who are educated and who have a previous experience of giving birth at institution.

The findings of this study have implications for policy, maternity care practice, and future research. With increasing focus on institutional birth with skilled birth attendants there is a fear that biomedical interventions overshadow the psychosocial model of care for women [33, 45]. Hence women's expectations need to be understood and addressed upon. Being treated with kindness and meeting their expectations increase women's satisfaction of childbirth experience [25, 46]. Cleanliness of maternity facilities and adequate beds and bed linens need to be ensured and privacy needs to be maintained. Reducing waiting time and providing adequate information are critical for increasing the likelihood to return in the future. Altogether, a renewed focus needs to be given to provide women with full information without having to wait for too long. They need to be provided with opportunity to ask questions and allowed to be involved in decision making. Further qualitative studies examining expectation of clients 
and satisfaction with self (internal control) need to be undertaken to better understand women's experiences. Response time (duration between calling for service and receiving service) need to be included as measures of satisfaction in future studies.

\section{Conclusion}

Mean satisfaction score was the highest for skill of service providers and the lowest for cleanliness of facilities. Satisfaction with information received was strongly correlated with politeness of staff, involvement in decision making, and satisfaction with overall care at facility. Willingness to return to facility showed a strong association with information received, waiting time, and overall care at facility. Hence, the measures to improve client experience of maternity care in Nepal should focus on improvement in physical environment along with improving attitude and communication skill of service providers with prompt response.

\section{Conflict of Interests}

The authors have no conflict of interests.

\section{Authors' Contribution}

Sarah Barnett, Deepak Paudel, Suresh Mehata, and Yuba Raj Paudel had the concept of the paper. Yuba Raj Paudel and Suresh Mehata conducted literature review, carried out the data analysis, and prepared the first draft. Stuart King, Sarah Barnett, Deepak Paudel, Maureen Dariang, and Krishna Kumar Aryal suggested the methodology and reviewed the paper. All authors read and agreed on the final version of paper.

\section{Acknowledgments}

The authors would like to thank all of the advisors of NHSSP. The STS 2013 was funded by UK Department for International Development (DFID).

\section{References}

[1] Department of Health Services, Annual Report-2012/13, Department of Health Services, Kathmandu, Nepal, 2014.

[2] Family Health Division, Aama Program Guideline, Second Revision 2069, Family Health Division, DoHS, Kathmandu, Nepal, 2012.

[3] Ministry of Health, New Era, and Macro International, Nepal Demographic and Health Survey 2006, Ministry of Health, New Era, Macro International, Calverton, Md, USA, 2007.

[4] Ministry of Health, New Era, and Macro International, Nepal Demographic and Health Survey 2011, Ministry of Health, New Era, Macro International, Calverton, Md, USA, 2012.

[5] Central Bureau of Statistics, Nepal Living Standard Survey2010/2011. Statistical Report, vol. 1, Central Bureau of Statistics, Kathmandu, Nepal, 2011.

[6] CBS, Nepal Multiple Indicator Cluster Surevy 2014: Key Findings, Central Bureau of Statistics, 2015.
[7] L. Hulton, Z. Matthews, and R. W. Stones, A Framework for the Evaluation of Quality of Care in Maternity Services, University of Southampton, Southampton, UK, 2000.

[8] D. Daniels, K. Ghimire, P. Thapa et al., The Mid Term Review of Nepal Health Sector Programme II (2010-2015), 2013, http:// www.nhssp.org.np/jar/NHSP\%20II\%20-\%20MTR\%20Report.pdf.

[9] Ministry of Health and Population, National Health Policy 2071, Ministry of Health and Population, Kathmandu, Nepal, 2014.

[10] R. Pittrof, O. M. R. Campbell, and V. G. A. Filippi, "What is quality in maternity care? An international perspective," Acta Obstetricia et Gynecologica Scandinavica, vol. 81, no. 4, pp. 277283, 2002.

[11] L. A. Hulton, Z. Matthews, and R. W. Stones, "Applying a framework for assessing the quality of maternal health services in urban India," Social Science and Medicine, vol. 64, no. 10, pp. 2083-2095, 2007.

[12] M. Redshaw, "Women as consumers of maternity care: measuring 'satisfaction' or 'dissatisfaction'?" Birth, vol. 35, no. 1, pp. 7376, 2008.

[13] J. M. Green and H. A. Baston, "Feeling in control during labor: concepts, correlates, and consequences," Birth, vol. 30, no. 4, pp. 235-247, 2003.

[14] M. Morgan, N. Fenwick, C. McKenzie, and C. D. A. Wolfe, "Quality of midwifery led care: assessing the effects of different models of continuity for women's satisfaction," Quality in Health Care, vol. 7, no. 2, pp. 77-82, 1998.

[15] L. Séguin, R. Therrien, F. Champagne, and D. Larouche, "The components of women's satisfaction with maternity care," Birth, vol. 16, no. 3, pp. 109-113, 1989.

[16] S. R. Baker, P. Y. L. Choi, C. A. Henshaw, and J. Tree, “I felt as though I'd been in Jail': women's experiences of maternity care during labour, delivery and the immediate postpartum," Feminism \& Psychology, vol. 15, no. 3, pp. 315-342, 2005.

[17] E. D. Hodnett, "Pain and women's satisfaction with the experience of childbirth: a systematic review," American Journal of Obstetrics \& Gynecology, vol. 186, no. 5, supplement, pp. S160S172, 2002.

[18] R. Amdemichael, M. Tafa, and H. Fekadu, "Maternal satisfaction with the delivery services in Assela Hospital, Arsi Zone, Oromia Region, Ethiopia, 2013," Obstetrics \& Gynecology (Sunnyvale), vol. 4, article 257, 2014.

[19] S. Agha, A. M. Karim, A. Balal, and S. Sosler, "The impact of a reproductive health franchise on client satisfaction in rural Nepal," Health Policy and Planning, vol. 22, no. 5, pp. 320-328, 2007.

[20] M. O. Audo, A. Ferguson, and P. K. Njoroge, "Quality of health care and its effects in the utilisation of maternal and child health services in Kenya," East African Medical Journal, vol. 82, no. 11, pp. 547-553, 2005.

[21] G. S. Lule, J. Tugumisirize, and M. Ndekha, "Quality of care and its effects on utilisation of maternity services at health centre level," East African Medical Journal, vol. 77, no. 5, pp. 250-255, 2000.

[22] A. Tayelgn, D. T. Zegeye, and Y. Kebede, "Mothers' satisfaction with referral hospital delivery service in Amhara Region, Ethiopia," BMC Pregnancy and Childbirth, vol. 11, no. 1, article 78, 2011.

[23] F. F. Al-Mailam, "The effect of nursing care on overall patient satisfaction and its predictive value on return-to-provider behavior: a survey study," Quality Management in Healthcare, vol. 14, no. 2, pp. 116-120, 2005. 
[24] A. N. Garman, J. Garcia, and M. Hargreaves, "Patient satisfaction as a predictor of return-to-provider behavior: analysis and assessment of financial implications," Quality Management in Health Care, vol. 13, no. 1, pp. 75-80, 2004.

[25] R. Hatamleh, I. A. Shaban, and C. Homer, "Evaluating the experience of Jordanian women with maternity care services," Health Care for Women International, vol. 34, no. 6, pp. 499$512,2013$.

[26] Ministry of Health and Population (MOHP), Health Research and Social Development Forum (HERD), and Nepal Health Sector Support Programme (NHSSP), Service Tracking Survey 2013, MOHP, HERD, NHSSP, Kathmandu, Nepal, 2014.

[27] R. Likert, "A technique for the measurement of attitudes," Archives of Psychology, vol. 22, no. 140, pp. 5-53, 1932.

[28] P. Goodman, M. C. Mackey, and A. S. Tavakoli, "Factors related to childbirth satisfaction," Journal of Advanced Nursing, vol. 46, no. 2, pp. 212-219, 2004.

[29] A. Rudman, B. El-Khouri, and U. Waldenström, "Women's satisfaction with intrapartum care-a pattern approach," Journal of Advanced Nursing, vol. 59, no. 5, pp. 474-487, 2007.

[30] S. Mehata, S. Lekhak, P. Chand, D. Singh, P. Poudel, and S. Barnett, Service Tracking Survey 2012, Ministry of Health and Population, Kathmandu, Nepal, 2013.

[31] Family Health Division and NHSSP, Responding to Increased Demand for Institutional Childbirths at Referral Hospitals in Nepal: Situational Analysis and Emerging Options, NHSSP, 2013.

[32] M. Klaus, J. Kennell, G. Berkowitz, and P. Klaus, "Maternal assistance and support in labor: father, nurse, midwife, or doula," Clinical Consultations in Obstetrics and Gynecology, vol. 4, no. 4, pp. 211-217, 1992.

[33] T. Kabakian-Khasholian, O. Campbell, M. Shediac-Rizkallah, and F. Ghorayeb, "Women's experiences of maternity care: satisfaction or passivity?" Social Science \& Medicine, vol. 51, no. 1, pp. 103-113, 2000.

[34] J. Senti and S. D. LeMire, "Patient satisfaction with birthing center nursing care and factors associated with likelihood to recommend institution," Journal of Nursing Care Quality, vol. 26, no. 2, pp. 178-185, 2011.

[35] J. K. Obamiro, "Effects of waiting time on patient satisfaction: Nigerian hospitals experience," The International Journal of Economic Behavior, vol. 3, no. 1, pp. 117-126, 2013.

[36] E. Kabali, C. Gourbin, and V. De Brouwere, "Complications of childbirth and maternal deaths in Kinshasa hospitals: testimonies from women and their families," BMC Pregnancy and Childbirth, vol. 11, no. 1, article 29, 2011.

[37] A. Jahn, M. D. Iang, U. Shah, and H. J. Diesfeld, "Maternity care in rural Nepal: a health service analysis," Tropical Medicine \& International Health, vol. 5, no. 9, pp. 657-665, 2000.

[38] S. Ng'anjo Phiri, K. Fylkesnes, A. L. Ruano, and K. M. Moland, "'Born before arrival': user and provider perspectives on health facility childbirths in Kapiri Mposhi district, Zambia," $B M C$ Pregnancy and Childbirth, vol. 14, no. 1, article 323, 2014.

[39] W. D. Klinkenberg, S. Boslaugh, B. M. Waterman et al., "Inpatients' willingness to recommend: a multilevel analysis," Health Care Management Review, vol. 36, no. 4, pp. 349-358, 2011.

[40] H. R. Rubin, B. Gandek, W. H. Rogers, M. Kosinski, C. A. McHorney, and J. E. Ware Jr., "Patients' ratings of outpatient visits in different practice settings: results from the medical outcomes study," The Journal of the American Medical Association, vol. 270, no. 7, pp. 835-840, 1993.
[41] M. Michael, S. D. Schaffer, P. L. Egan, B. B. Little, and P. S. Pritchard, "Improving wait times and patient satisfaction in primary care," Journal for Healthcare Quality, vol. 35, no. 2, pp. 50-60, 2013.

[42] N. A. Khan, S. K. Aslam, A. U. Rehman et al., "Satisfaction level and its predictors among out patients at public sector hospital in Karachi," Journal of Dow University of Health Sciences, vol. 8, no. 3, 2014

[43] D. Polit and C. Beck, Nursing Research: Principles and Methods, Lippincott Williams \& Wilkins, Philadelphia, Pa, USA, 2004.

[44] J. E. Soet, G. A. Brack, and C. Dilorio, "Prevalence and predictors of women's experience of psychological trauma during childbirth," Birth, vol. 30, no. 1, pp. 36-46, 2003.

[45] P. Larkin, C. M. Begley, and D. Devane, "Women's experiences of labour and birth: an evolutionary concept analysis," Midwifery, vol. 25, no. 2, pp. e49-e59, 2009.

[46] S. Hassan-Bitar and L. Wick, "Evoking the guardian angel: childbirth care in a palestinian hospital," Reproductive Health Matters, vol. 15, no. 30, pp. 103-113, 2007. 


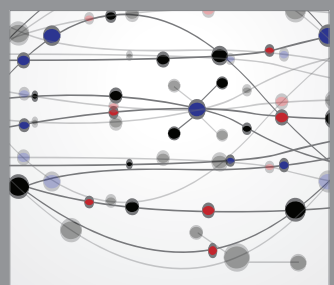

The Scientific World Journal
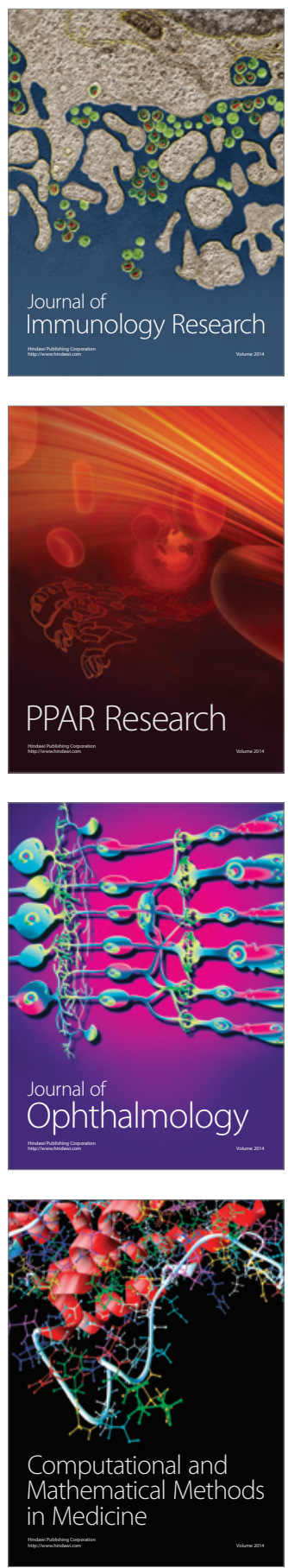

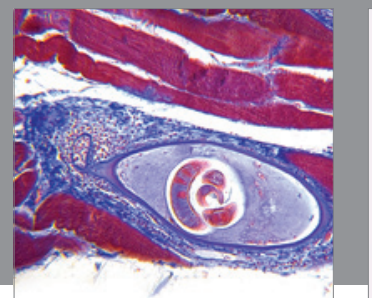

Gastroenterology

Research and Practice
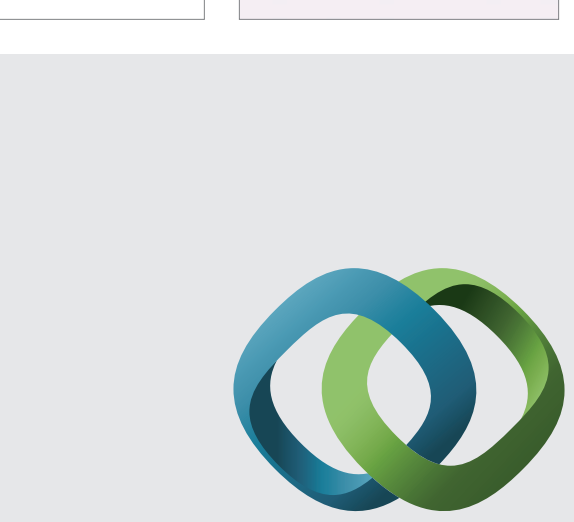

\section{Hindawi}

Submit your manuscripts at

http://www.hindawi.com
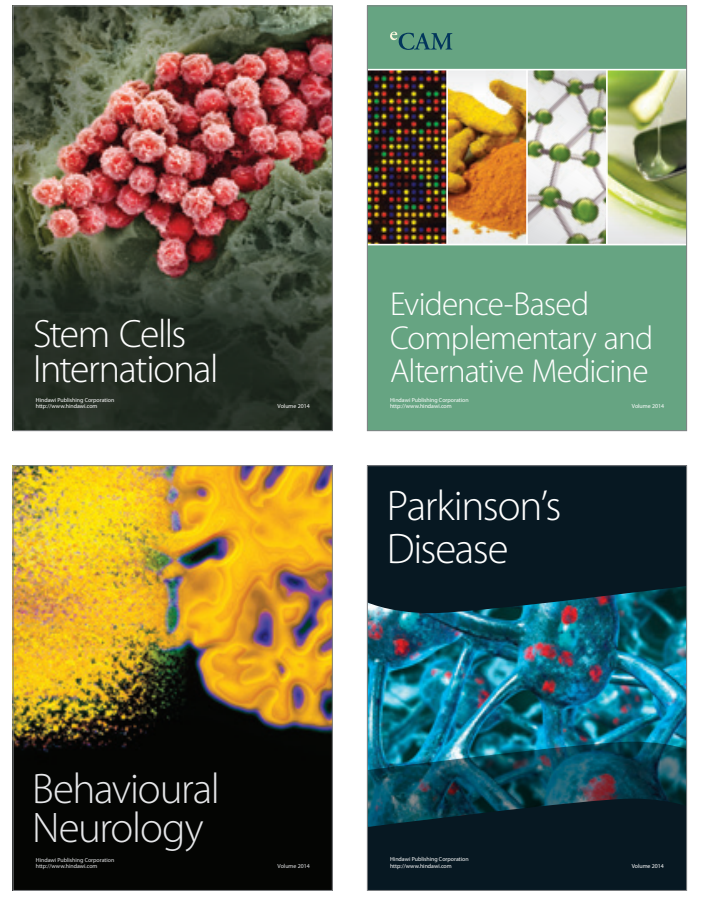
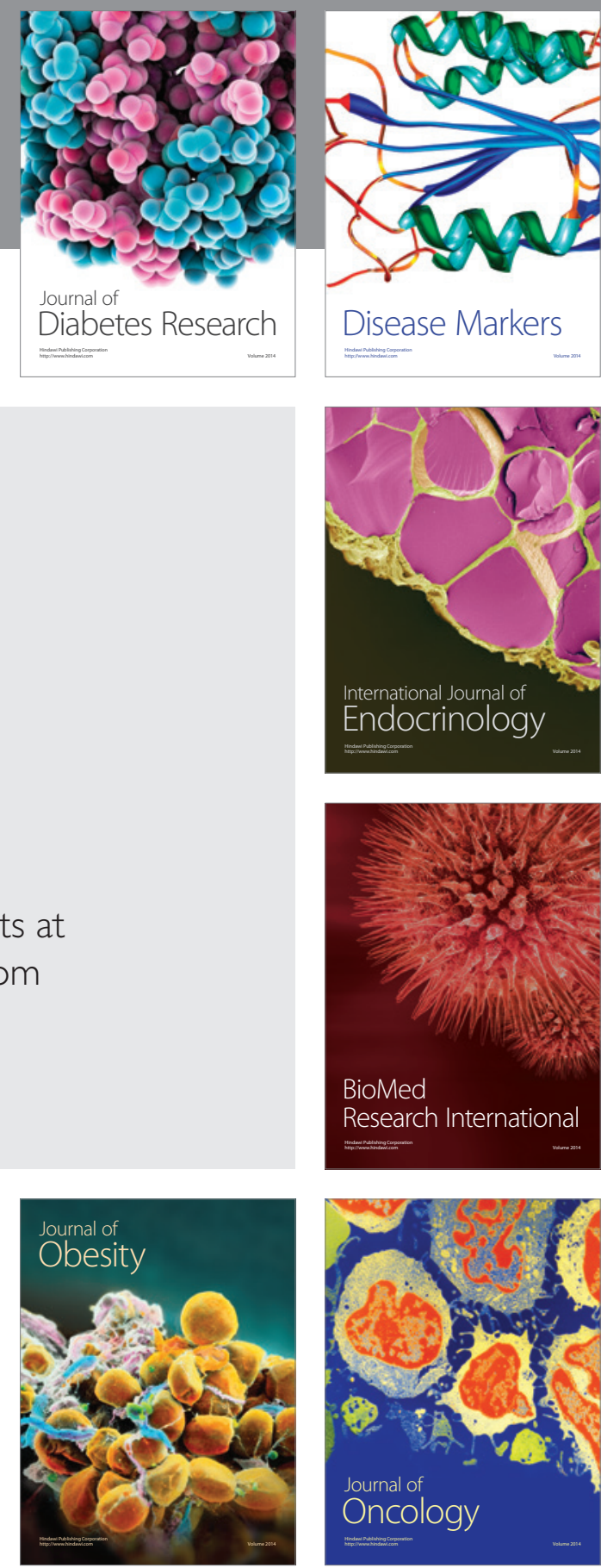

Disease Markers
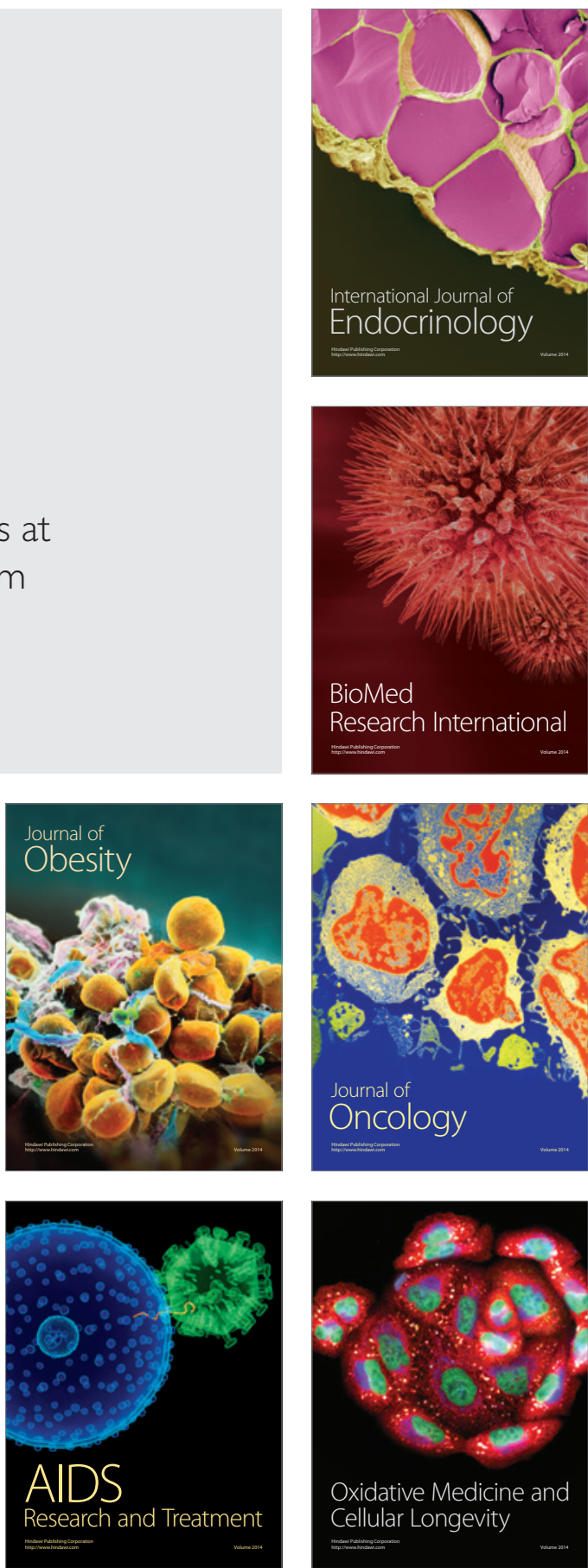